\title{
Prolonged exposure to conspecific and predator odors reduces fear reactions to these odors during subsequent prod-shock tests
}

\author{
JON L. WILLIAMS, AMY G. ROGERS, and ALISON P. ADLER \\ Kenyon College, Gambier, Ohio
}

\begin{abstract}
In Experiment 1, four groups of male rats were given a session as an intruder in either aggressive (i.e., alpha) or nonaggressive colonies of conspecifics and later received either a 2-h exposure to the odors of the alpha colonies or an exposure-control session with the odors of a nonalpha colony. Two additional groups of rats that had been attacked and defeated by alpha residents were later given a 12-h exposure session with alpha-colony odors or nonalpha-control odors. Twentyfour $h$ after the colony-intruder session, all subjects were given a single 6.5-mA shock from a prod with alpha-colony odors present in the bedding of the test chamber. Attacked rats that had been given exposure-control sessions showed significantly less prod burying and greater freezing than nondefeated subjects. This implies that the alpha-colony odors elicited conditioned fear. In contrast, the attacked subjects that had been given a pretest exposure session with alpha-colony odors showed significantly more prod burying and significantly less freezing. This suggests that the alpha-odor exposure resulted in the extinction of fear to these odors. Furthermore, the 12-h exposure to alpha-colony odors was found to be more effective in reducing fear-mediated responses than was the 2-h exposure. In Experiment 2, three groups of rats were exposed to a cat while they were in a protective cage; later they were given a 12-h exposure session with cat odors, a 12-h exposure-control session with no cat odors, or no exposure treatment. Compared with the two control groups, the subjects that were exposed to cat odors showed less freezing during subsequent prod-shock tests in the presence of cat odors, but they did not show prod burying. The reported changes in fear-mediated reactions to the odors of conspecifics and a predator are discussed in terms of both associative and nonassociative processes.
\end{abstract}

Over the past several years, considerable research has examined the influence that both laboratory and natural stressors, and their related odors, have on subsequent fearmediated responses produced by the use of the prod-shock procedure (see Williams, 1987a, 1989, for reviews). This procedure, which has been extensively studied by Pinel and his colleagues (e.g., Pinel \& Treit, 1978, 1981), consists of administering a single electric shock from a prod that is mounted on the wall of a chamber with movable bedding material on the floor. When tested with this procedure, rats typically show a brief freezing reaction following the prod shock, and then they bury the prod with the bedding material. Although Pinel has interpreted this type of prod burying to be a conditioned defensive response (Pinel \& Treit, 1978, 1981; Treit, 1985), others have claimed that it is an example of shock-elicited spraying or burrowing (Fanselow, Sigmundi, \& Williams, 1987; Peacock \& Wong, 1982). Numerous studies by Williams

This research was supported by USPHS Research Grant 1-R01NH43815-02 and endowment funds available to the senior author from the Samuel B. Cummings, Jr., Professorship in Psychology. The authors wish to thank Dr. Arthur Leccese and Paul Worland for their helpful suggestions in the preparation of this manuscript. Correspondence should be addressed to Jon L. Williams, Department of Psychology, Kenyon College, Gambier, OH 43022. and his colleagues (e.g., Williams, 1987b; Williams \& Scott, 1989) have consistently found that exposure to stress and later testing in a feared context results in suppression, as opposed to enhancement, of prod burying. These findings suggest that while burying may be elicited by the fear of a localized source of shock, it is unlike most defensive behaviors in that it is disrupted by the presence of contextual fear stimuli.

Despite the controversy concerning the nature and precise function of prod-burying behavior, numerous investigators have found this paradigm to be very useful in assessing fear and/or anxiety, particularly when observations are also made of concurrent responses, such as freezing (Peacock \& Wong, 1982; Williams \& Scott, 1989). Moreover, this technique is especially well suited for measuring conditioned and unconditioned fear reactions to contextual odor cues because they can be added to the bedding material of the test chamber, thus requiring the subject to have direct contact with these odors when manipulating the bedding (see Williams, 1987b, 1989 , for further details). Finally, this paradigm is effective in terms of assessing long-term reactions to stress exposure because the shock from the prod functions as a priming stimulus. Priming has been found by many investigators to be important in terms of mediating the longterm (i.e., 24-h) effects of prior exposure to a variety of 
stressors (e.g., Maier, 1986; Williams, Worland, \& Smith, 1990).

Using the prod-shock paradigm, Williams (1987b) reported that prior exposure to a series of inescapable shocks and the presence of the odors from shocked conspecifics at the time of testing separately produced decreases in prod burying and increments in freezing. Moreover, these response changes were found to be significantly augmented for subjects that received the combination of prior shock and testing with conspecific stress odors. These response augmentations were interpreted as being the result of both fear conditioning and nonassociative sensitization processes.

Recent research has examined the extent to which various ethological stressors can influence an organism's behavior when it is later tested in the presence of the odors associated with the stress situation. For example, Williams and Lierle (1988) reported that rats show less exploration and deficits in shock-escape learning if they have been given repeated sessions consisting of being attacked and defeated by aggressive, or alpha, conspecifics and are later tested in the presence of the odors of the alpha colony. In addition, Williams and Scott (Experiment 1, 1989) have recently reported that a single session of alpha attack is sufficient to alter subsequent responses during prod-shock tests. Male rats were exposed to either aggressive alpha colonies or nonaggressive colonies and tested $24 \mathrm{~h}$ later with the colony odors of alpha or nonalpha rats added to the bedding of the prod-shock chamber. The results of this study indicated that neither a prior session of being defeated nor the presence of alpha-colony odors during testing altered prod burying or freezing. However, the combination of these two factors significantly decreased prod burying and increased freezing. These findings, as well as results of other research (Williams et al., 1990), suggest that the augmented fear reactions to alpha-colony odors following a session of alpha attack are primarily the result of fear conditioning.

Another type of natural stressor for the rat is exposure to a cat when confined in a protective cage (e.g., Blanchard \& Blanchard, 1971; Blanchard, Fukunaga, \& Blanchard, 1976). Williams and Scott (Experiment 2, 1989) examined the effects of this type of stressor during subsequent prod-shock tests with cat odors either present or absent. The results of this study indicated that prior exposure to a cat had very little effect on burying or freezing. However, it was difficult to determine the precise effects of cat exposure in this experiment since the presence of cat odors during testing completely eliminated prod burying, thus producing a possible floor effect. The presence of cat odors during testing was also found to produce very little freezing. Instead, the subjects spent most of the test session slowly exploring the cat-odor bedding with an outstretched posture, which is considered by some researchers to be an example of "risk-assessment" defensive behavior (Blanchard \& Blanchard, 1989; Blanchard, Blanchard, \& Hori, 1989). Although these findings indicate that cat odors are innately feared by rats,
Williams and Barber (1990) recently found that exposure to a cat is capable of enhancing amphetamine-induced stereotypy when cat odors are present during subsequent drug testing. The augmentation of this stress reaction suggests that prior exposure to a cat may have resulted in fear conditioning and/or sensitization to innately feared cat odors.

The major purpose of the present research is to determine if exposure to the odors of alpha colonies or cats, following a session of attack by an alpha rat or exposure to a cat, respectively, is capable of attenuating the fear reactions that rats typically show when these odors are later present during prod-shock testing. Support for this prediction is found in the literature on the extinction of avoidance responses (e.g., Baum, 1970; Levis, 1989; Mineka, 1979) and in flooding studies done with fear of snakes in primates (Mineka, 1987; Mineka \& Keir, 1983).

\section{EXPERIMENT 1}

The first objective of this experiment was to replicate the findings of Williams and Scott (Experiment 1, 1989), which showed that attack by an alpha resident is a necessary condition for a reduction in subsequent prod burying and an increase in freezing when alpha-colony odors are present in the test chamber. The second objective was to determine if these fear-mediated reactions to alphacolony odors could be extinguished by exposing defeated rats to alpha-colony odors, as opposed to control odors from nonalpha conspecifics, prior to a prod-shock test session. Finally, this experiment was conducted to determine if the total duration of exposure to the feared alpha-colony odors is a critical factor in extinguishing subsequent fearmediated reactions. In a recent review, Levis (1989) concluded that the extinction of fear in avoidance learning was a direct function of the total amount of CS exposure. Therefore, it was predicted that a $12-\mathrm{h}$ exposure to alphacolony odors, compared with a 2 -h exposure, would be more effective in extinguishing these fear reactions when subjects were tested in the presence of alpha-colony odors.

\section{Method}

Subjects. Forty-eight male albino rats of Holtzman descent, weighing $458-529 \mathrm{~g}$, were used as subjects. They were maintained on a 12:12-h reverse light:dark cycle and were given free access to food and water throughout the experiment in their individual, rack-suspended cages. Four colonies of two, two-year old male rats and one younger adult female rat were used for resident-intruder exposure. Based on the results of a series of previous residentintruder tests, one (or sometimes both) of the rats in two of these colonies (i.e., alpha colonies) was found to be consistently aggressive, whereas both the males in the remaining two colonies were found to be nonaggressive (i.e., nonalpha colonies).

Apparatus. The four colonies were each housed in $50 \times 40 \times$ 20 -cm polypropylene tubs with stainless steel wire tops. The floors of the colonies were covered with ground corncob bedding material (i.e., "Bed-O' Cobs"), that is commercially available from The Andersons, Industrial Products Division, Maumee, Ohio.

Four metal boxes, each $36 \times 36 \times 41 \mathrm{~cm}$ with a Plexiglas top, were used as alpha-odor exposure chambers or as exposure-control cham- 
bers. The bottom of each box was covered with an 8-cm layer of corncob bedding material. The two boxes used as alpha-odor exposure chambers were located in a separate room from the two boxes used to provide the exposure-control treatment. A noise generator produced a background sound of white noise ( $75 \mathrm{~dB}$ SPL) in the two rooms.

The two test chambers used for prod-shock testing, and four identical chambers used for the initial habituation sessions, were metal $36 \times 36 \times 41-\mathrm{cm}$ boxes with an opening at the top that was fitted with a Plexiglas lid. The bottom of each box was covered with an $8-\mathrm{cm}$ layer of corncob bedding material. On one side of the box, $2 \mathrm{~cm}$ above the bedding material, was a wooden dowel which protruded $6 \mathrm{~cm}$ from the wall. The dowel was $15 \mathrm{~mm}$ in diam and was wrapped with two uninsulated copper wires. Shock presentations through the prod were controlled manually and were administered from a Lafayette 82400 shock source. A white-noise generator, identical to one previously described, produced a background sound that was sufficient to attenuate potentially distracting noises. The prod-shock chambers were located in a separate room from the habituation, alpha-odor exposure, and exposurecontrol chambers. A Panasonic WV-3260 video camera was mounted above the test chamber, which was illuminated by a 15 -watt incandescent bulb that was $3 \mathrm{~m}$ above the chamber. The behavior of the subjects was viewed and recorded by means of videotape equipment and a color monitor that were located in an adjacent room.

Procedure. All 48 subjects were initially habituated to chambers that were identical to the test chambers with the use of the following procedure. On Days 1 and 2, they were habituated to the chambers in pairs; on Days 3 and 4, they were given individual habituation to the same chambers. All of these initial habituation sessions were for a 35-min period.

During the morning of Day 5, 48 rats were randomly assigned to be subjects in six groups. The rats in four groups were given a 15-min defeat (D) session as an intruder in one of the aggressive colonies, and the subjects in the remaining two groups were intruders for $15 \mathrm{~min}$ in one of the nonaggressive colonies where they were not defeated (ND). ${ }^{1}$ Before the resident-intruder session, the colony females were removed, and the intruders were marked on their backs with a colored marker for the purpose of easy identification. The subjects were individually used as intruders in their assigned aggressive or nonaggressive colonies. Immediately following the resident-intruder session, each subject was returned to its home cage, and samples of the soiled bedding from the alpha colonies were collected for the purpose of odor manipulations to be performed during later odor-exposure sessions and prod-shock test sessions.

During the afternoon and evening of Day 5 , the subjects in one of the ND groups and in one of the D groups were given either a 2-h session of exposure to alpha-colony odors (E2) or a 2-h session of exposure to control odors from the bedding of nonalpha conspecifics (EC2). Two other groups of defeated subjects received either a 12-h colony-odor exposure session (D/E12) or a 12-h exposure-control session (D/EC12) with control odors. Before each alpha-odor exposure session, 1 liter of soiled bedding from the alpha-colony cages was evenly distributed over the top of the clean bedding material on the floor of the exposure chambers. For subjects in the exposure-control groups, the same amount of soiled bedding from the final habituation session was evenly spread over the bedding floor of their chambers. Originally, the soiled bedding from the two nonalpha colonies was to be added to the bedding of the exposure-control chamber. However, the odors from these colonies were not considered to be suitable control odors, because several bouts of fighting occurred between the residents of these colonies shortly after the resident-intruder sessions.

On Day 6, $24 \mathrm{~h}$ after each subject was used as a colony intruder, all the rats were individually placed in the prod-burying chamber with 1 liter of soiled bedding from the cages of the alpha rats evenly distributed on top of the bedding floor of the chamber. Then the Plexiglas lid to the chamber was closed, the video camera was positioned above the chamber, and the experimenter went into the adjoining room to observe the subject on the monitor. Upon their initial contact with the prod, usually within $30 \mathrm{sec}$, the subjects were manually given a very brief (i.e., less than $100 \mathrm{msec}$ ) 6.5 -mA shock. Following the prod shock, the rats were observed for a period of $20 \mathrm{~min}$, and their cumulative burying and freezing times were recorded. Freezing was scored if the rat assumed a crouched posture and ceased all body and head movement except for the vibrissae. Both the total duration and the location of freezing were recorded throughout the session. If the rat buried the prod, the height of the tallest pile of bedding, within $5 \mathrm{~cm}$ of the prod, was measured and recorded. The responses of the rats during prod-shock testing were recorded by an experienced observer using a chart recorder. Previous videotaped observations had ascertained that the interreliability of scoring for all of these measures exceded .95. The test chambers were cleaned with an industrial vacuum, and all surfaces were washed with a $5 \%$ solution of ammonium hydroxide between sessions that involved different experimental treatments.

\section{Results and Discussion}

All of the rats that were used as intruders in colonies with aggressive alpha males received from 4 to 6 bites; these were consistently made on the intruder's back. An analysis of variance revealed that the mean numbers of bites received by the rats in the four defeated groups did not differ significantly from one another at the .05 level.

The mean latencies for each group of subjects to touch the prod and receive a single electric shock were between 22.40 and $30.34 \mathrm{sec}$, and the results of an ANOVA indicated that the six group means were not significantly different from one another at the .05 level. It should be noted that these latencies were not considered to be a good measure of the subject's fear of the alpha-colony odors in the test chamber, because the rats probably had not yet recovered from being placed in the chamber and having the experimenter adjust the camera before leaving the room. All of the rats showed erratic exploratory/flight behavior prior to the time they made contact with the electrified prod.

The mean durations of burying responses following the prod shock for all six groups of subjects, tested with the alpha-colony odors in the bedding material, are presented in Figure 1. The results of a one-way ANOVA indicated that the overall main effect between the six groups was statistically significant $[F(5,42)=14.23, p<.001]$. Planned-comparison tests (Winer, 1971) revealed that the subjects in the ND groups that had either an EC2 or an E2 before prod-shock testing showed significantly ( $p s<$ $.01)$ more prod burying than did the two defeated groups that had the exposure to the control odors (i.e., Groups $\mathrm{D} / \mathrm{EC} 2$ and $\mathrm{D} / \mathrm{EC} 12$ ). Additional planned-comparison tests indicated that defeated subjects showed a partial recovery in burying after a 2-h colony-odor exposure, Group D/E2 showed significantly more burying than did Group D/EC2 $(p<.05)$, and the 12-h exposure subjects in Group $\mathrm{D} / \mathrm{E} 12$ buried significantly more than did the rats in Group D/E2 $(p<.05)$ and in Group D/EC12 
$(p<.01)$. Moreover, the rats in Group D/E12 buried as much as the subjects in the two ND control groups.

Figure 2 presents the mean height of the tallest piles of bedding that the rats made in the vicinity of the shock prod, for all six groups, when they were tested with the alpha-colony odors in the bedding of the test chamber. The general pattern of the differences between the groups is very similar to the duration of burying data seen in Figure 1. However, compared with prod burying, there was much more within-group variability in these scores as reflected by the relatively large standard-error bars. The results of a one-way ANOVA revealed that the overall main effect between the six groups was statistically significant $[F(5,42)=2.48, p<.05]$. Planned-comparison tests (Winer, 1971) indicated that the rats in the nondefeated groups made significantly higher piles than the defeated subjects in Group D/EC2 $(p<.05)$. In addition, the rats that had a 12 -h exposure to the colony odors, in Group $D / E 12$, made higher piles than the subjects in Groups D/EC2, D/E2, and D/EC12 ( $p s<.05$ ). Perhaps because of the large within-group variance, no other meaningful comparisons were found to be statistically significant at the .05 level.

Figure 3 shows the mean duration of freezing for all six groups when tested, following prod shock, with alphacolony odors present in the test bedding. These results show a pattern of group means that is basically the inverse of the burying data shown in Figures 1 and 2. The outcome of a one-way ANOVA revealed that the overall main effect between the six groups was statistically significant $[F(5,42)=15.97, p<.001]$. Planned-comparison tests (Winer, 1971) showed that the two nondefeated groups spent significantly less time freezing than did the defeated exposure-control subjects in Group D/EC2 $(p<$

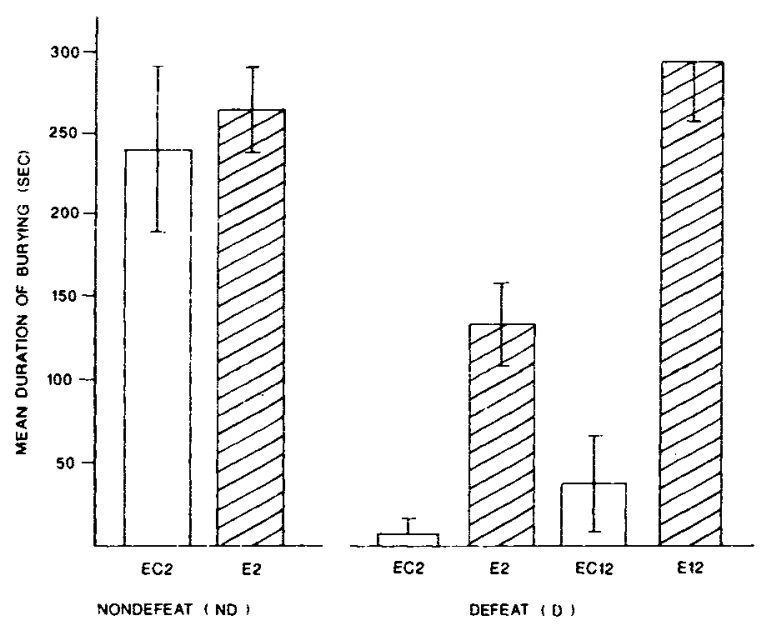

Figure 1. Mean duration of burying by nondefeated intruders (ND) and defeated intruders (D) that were later given either a 2-h or a 12-h session of exposure control (EC) to the odors of nonalpha rats or exposure (E) to the odors of the alpha colonies. All subjects were given prod-shock tests $24 \mathrm{~h}$ after the colony-intruder session with alpha-colony odors present in the bedding of the test chamber.

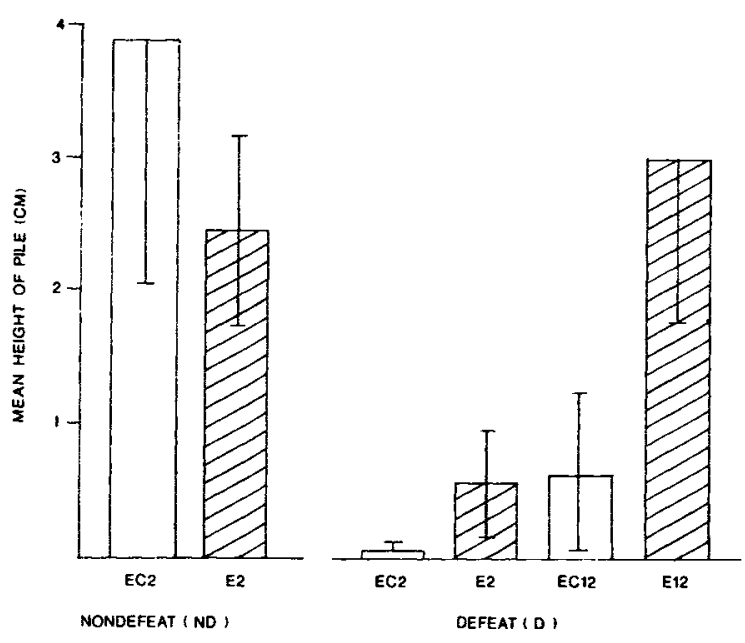

Figure 2. Mean height of bedding piles by nondefeated intruders (ND) and defeated intruders (D) that were later given either a 2-h or a 12-h session of exposure control (EC) to the odors of nonalpha rats or exposure (E) to the odors of the alpha colonies. All subjects were given prod-shock tests $24 \mathrm{~h}$ after their colony-intruder session with alpha-colony odors present in the bedding of the test chamber.

$.01)$ and in Group D/EC12 $(p<.05)$. Additional planned tests revealed that the rats in the two colony-odor exposed conditions (i.e., Groups D/E2 and D/E12) showed significantly less freezing than did the subjects in the D/EC groups that had comparable durations of exposure to control odors $(p s<.01)$. It is also important to mention that at no time did a subject show freezing within $10 \mathrm{~cm}$ of the prod, suggesting that the prod was indeed a localized source of fear.

Pearson correlation tests were conducted to examine the possible relationships among the three dependent variables within each of the groups. The only correlation values that were found to be statistically significant were between the duration of burying and the heights of the piles for Group ND/EC $[r(6)=+.98, p<.01]$, Group D/EC12 $[r(6)=+.98, p<.01]$, and Group D/E12 $[r(6)=+.73$, $p<.05]$. The possibility of finding significant correlation values was obviously hindered by the fact that there were only 8 subjects per group. Therefore, it may be useful to note that the within-groups correlations that exceeded an $r$ value of .35 were: +.49 between burying and heights of pile in Group $D / E 2,-.59$ between freezing and burying in Group ND/E2, and -.53 between freezing and burying for Group D/E2.

The findings of this experiment replicate those reported by Williams and Scott (Experiment 1, 1989), who found that prior attack by an alpha conspecific is a necessary condition for rats to show a later suppression in prodshock burying and an increase in freezing when alphacolony odors are present in the test bedding. More importantly, pretest exposure to alpha-colony odors clearly resulted in the significant attenuation of these fearmediated alternations in behavior, probably as a result of the experimental extinction of fear. This interpretation is 


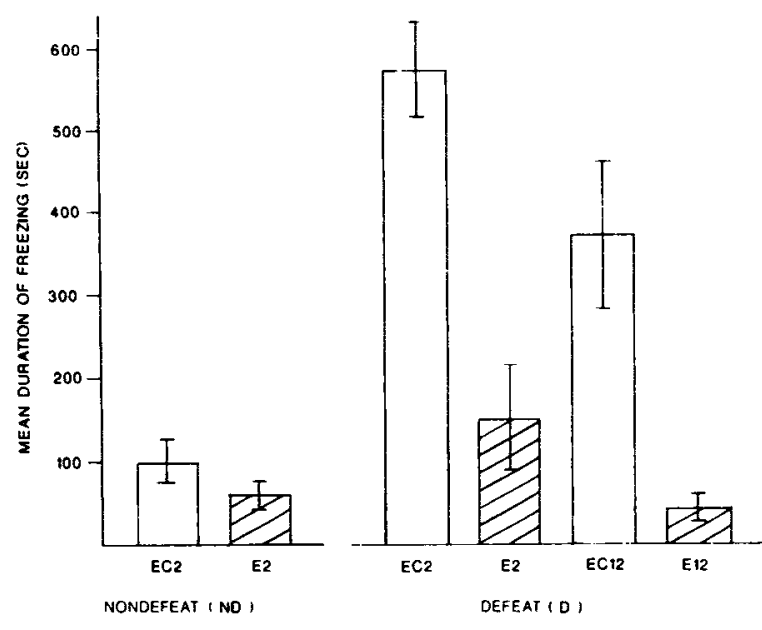

Figure 3. Mean duration of freezing behavior by nondefeated intruders (ND) and defeated intruders (D) that were later given either a 2-h or a 12-h session of exposure control (EC) to the odors of nonalpha rats or exposure (E) to the odors of the alpha colonies. All subjects were given prod-shock tests $24 \mathrm{~h}$ after their colony-intruder session with alpha-colony odors present in the bedding of the test chamber.

also consistent with the finding that a 12-h pretest exposure to the feared alpha-colony odors, for alpha-attacked rats, produced significantly greater reductions in subsequent fear reactions than did a 2-h pretest exposure.

\section{EXPERIMENT 2}

Williams and Scott (Experiment 2, 1989) reported that cat odors, obtained from the hair and soiled litter of cats, produced a disruption in prod burying regardless of whether or not the rats had been previously exposed to a cat. This suggests that the rat's fear of cat odors is an unconditioned response. For some time it has been known that rats show freezing and opioid analgesia when they are exposed to a cat (e.g., Blanchard, Fukunaga, \& Blanchard, 1976; Lester \& Fanselow, 1985). Recently, Williams and Barber (1990) found that exposure to a cat is also capable of enhancing amphetamine-induced stereotypy, especially when cat odors are present during subsequent drug testing. This finding suggests that prior exposure to a cat may result in fear conditioning and/or sensitization to innately feared cat odors.

In light of the fear-reducing effects that a pretest exposure to alpha-colony odors had for the colony-defeated rats in Experiment 1, it was hypothesized that a pretest exposure to cat odors, following protected exposure to a pair of cats and their odors, would also attenuate the fear-mediated responses during subsequent prod-shock tests with cat odors present. Specifically, the abbreviated design of Experiment 2, in comparison with Experiment 1, consisted of separate groups of cat-exposed rats that were later given (a) a 12-h exposure session with cat odors, (b) a 12-h exposure-control session with conspecific odors, or (c) no specific treatment (i.e., they re- mained in their individual home cages). As in the study of Williams and Scott (Experiment 2, 1989), the cat odors consisted of a sample of cat hair and soiled cat litter that was originally unscented. Twenty-four $h$ after their catexposure session, the subjects in all three groups were tested with the cat-odor stimuli added to the bedding of the prod-shock chamber.

\section{Method}

Subjects. Twenty-four male albino rats of Holtzman descent, weighing $375-415 \mathrm{~g}$ at the start of the experiment, served as subjects. They were maintained on a 12:12-h light:dark cycle, and food and water were continuously available in the individual cages. In addition, one adult female and four aduit neutered male cats, housed in a separate laboratory area, were used as predatory stressors.

Apparatus. The cats were housed with free access to food and water, and two litter boxes, in a $3.5 \times 4.0 \mathrm{~m}$ room in which they were free to roam. A small hole in the door of the room enabled the experimenter to observe the area with a television camera and monitor that was located outside the door in an adjacent room. Subjects were exposed to cats in a wire-cloth cage that was $31 \mathrm{~cm}$ long $\times 20 \mathrm{~cm}$ wide $\times 20 \mathrm{~cm}$ high. The rat's small exposure cage was placed between two larger carrying cages that were each used to house a cat during cat-exposure sessions. The wire-cloth sides and top of the rat's cage and the large openings on the doors of the cats' cages allowed for excellent visual, auditory, and olfactory transmission of cues, but actual physical contact with the rat by the cats was not possible because of the small openings in the wire cloth of the rat's cage.

The four metal boxes that were used as the exposure and exposurecontrol chambers in Experiment 1 were thoroughly cleaned and used for the same purpose in this experiment. Likewise, the two prodshock burying chambers, electric shockers, background noise generators, and video equipment were the same as those used in Experiment 1.

Procedure. All 24 rats were habituated to the prod-shock test chambers for 35-min sessions for four consecutive days, using the same procedure that was described in Experiment 1.

On the morning of Day 5 , the rats were randomly assigned to three groups of 8 subjects each, and all subjects were exposed to cats in the room where the cats were housed. At the start of this session, each rat was placed inside the small, wire-cloth exposure cage, and two randomly selected male cats were placed inside separate carrying cages. The cat cages were then positioned so that the large openings in the doors of these cages were directly facing the front and back of the rat's cage, ensuring the proximity of the cats and the rat. Two litter boxes, each containing soiled cat litter and cat hair, were placed on either side of the rat's cage in order to make the cat odors as salient as possible. The three cats that were not in the carrying cages remained in the room during these sessions, and they could freely explore the outside of the rat's cage. The cat-exposure sessions lasted for $30 \mathrm{~min}$, after which the rat was returned to its home cage, the cats were removed from the carrying cages, and samples of cat odors and cat hair were obtained from the soiled bedding of their litter boxes. Throughout this session, the behavior of the subjects was observed and recorded by means of the video camera and videotape equipment in the adjacent room. Freezing was scored if the rat assumed a crouched posture and ceased all body and head movement except for the vibrissae.

During the evening of Day 5, the subjects in Group $E$ were given a 12-h session of exposure to cat odors. Before each animal was placed in the exposure chamber, 1 liter of soiled cat litter containing cat hair was evenly distributed over the top of the clean bedding material on the floor of the chamber. For the exposure-control subjects in Group EC, the same amount of soiled bedding from the final habituation session was evenly spread over the bedding floor 
of their chambers. These subjects were also confined to the exposurecontrol chamber for a period of $12 \mathrm{~h}$. The exposure and exposurecontrol chambers were located in separate rooms where background white noise was presented during the entire session. Following these sessions, each subject was returned to its home cage. The rats in Group C served as control subjects, and they were not handled or removed from their home cages during this phase of the experiment.

On Day 6, $24 \mathrm{~h}$ after the rats had been exposed to the cats, each subject was placed in the prod-shock apparatus after 1 liter of soiled cat litter and cat hair had been evenly spread over the top of the bedding on the floor of the chamber. Shortly after being placed in the test chamber, the rats were each given a brief prod shock, and their behavior was observed for $20 \mathrm{~min}$. The durations of burying and freezing and the heights of bedding piles were recorded with the use of the procedures described in Experiment 1.

\section{Results and Discussion}

All three groups of rats showed a great deal of freezing behavior during the 30-min cat-exposure session, with the means for each group being 1,150,1,374, and 1,290 sec. Thus, when the rats were actually threatened by the cats during the exposure session, the mean percentages of time that the groups spent freezing were $63.89 \%, 76.38 \%$, and $71.67 \%$. As expected, the results of a one-way ANOVA revealed that the amounts of freezing by these groups did not differ from one another at the .05 level. In addition, relative to the single cat-exposure procedure employed by Williams and Scott (Experiment 2, 1989), the use of a pair of threatening cats in this experiment was far more effective in terms of producing high levels of freezing.

Following the prod shock, it was somewhat surprising that none of the rats in this experiment even attempted to use the cat-odor bedding to bury the prod. In contrast to the results of Experiment 1, which involved prod-shock testing of defeated subjects in the presence of alpha-colony odors, the duration of burying and the height of pile scores were zero for every subject in this experiment. Therefore, based on the prod-burying results, neither the 12-h cat-odor exposure nor the 12-h exposure-control sessions were effective in terms of reducing the subject's fear of the cat odors during testing.

Figure 4 presents the mean duration of freezing for the three groups following prod shock in the presence of cat odors. Consistent with our original predictions and the data from Experiment 1, the 12-h cat-odor exposure treatment (i.e., Group E) showed a $66.78 \%$ reduction in postshock freezing in the presence of cat odors, relative to the control group of rats that remained in their home cages (i.e., Group C). Finally, the 12-h exposure-control condition (i.e., Group EC) was found to produce a $22.46 \%$ reduction in freezing relative to the control group. Although the results of a one-way ANOVA failed to show that the amount of freezing among the three groups differed significantly at the .05 level, two one-tailed $t$ tests indicated significant differences in freezing between Group $\mathrm{E}$ and Group $C[t(14)=2.22, p<.05]$ and between Group $\mathrm{E}$ and Group EC $[t(14)=1.85, p<.05]$, whereas no significant difference was found between Group EC and Group $C$ at the .05 level.

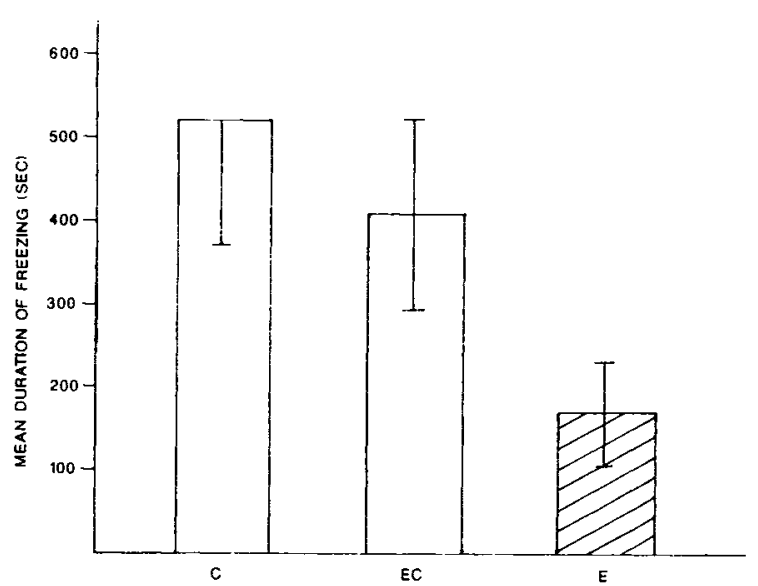

Figure 4. Mean duration of freexing shown by rats that were previously exposed to cats and cat odors, while they were in a protective cage, and later given a 12-h session of exposure $(E)$ to cat odors, a 12-h session of exposure control (EC) to conspecific odors, or remained in their home cages as a control (C) group. All subjects were given prod-shock tests $24 \mathrm{~h}$ after their cat-exposure session with cat odors present in the bedding of the test chamber.

The findings of this exploratory study suggest that pretest exposure to cat odors attenuated subsequent freezing when the subjects were later tested with prod shock in the presence of cat odors. It is interesting to note that all of the subjects in this experiment continually explored the cat-odor bedding after they stopped freezing, and none of them showed prod burying. Williams and Scott (Experiment 2,1989 ) also found this type of exploratory behavior had precedence over prod burying during tests with cat odors. Finally, Fanselow and Lester (1988, pp. 199201) have reported that the actual presence of a cat during testing reduced the manipulation of unscented sawdust in rats.

\section{GENERAL DISCUSSION}

The results of Experiment 1 replicated the findings of Williams and Scott (Experiment 1, 1989) in showing that one session of attack by an alpha conspecific, combined with later testing in the presence of alpha-colony odors, disrupts prod burying and increases freezing. Postshock freezing by the rats in both of the present experiments, as well as in the studies of Williams $(1987 \mathrm{~b})$ and Williams and Scott (Experiments 1 and 2, 1989), consistently took place in one of the two corners of the chamber that were farthest from the prod. This implies that, even though the rats feared the various stress odors (i.e., odors from shocked conspecifics, alpha colonies, or cats), they nevertheless perceived the prod as a localized source of fear. This finding also suggests that the observed suppressions in prod burying in the presence of contextual fear odors were not the result of blocking, overshadowing, conditioned analgesia, or some other mechanism that might have prevented the prod from becoming an effec- 
tive CS. Therefore, it appears that the suppression in burying in the presence of contextual fear odors is the result of performance factors operating at the time of testing (e.g., fear sensitization, competing responses), as opposed to learning processes that may have occurred as a result of the prod shock. Further experiments involving odor manipulations during prod-shock conditioning and subsequent testing are being conducted in an attempt to resolve this issue.

The manipulation of the fear odors in Experiment 1, as well as in the study by Williams and Scott (Experiment 1,1989 ), was done by transporting samples of soiled bedding from the alpha colonies to the prod-shock testing environment. The alpha-colony bedding obviously contained the odors of the alpha animal as well as the odors of the subordinate male and female colony residents. In addition, the alpha-colony bedding may have also contained the stress odors of attacked intruders, including the intruder's own stress odors. Therefore, a variety of conspecific odors could have become conditioned fear stimuli during the resident-intruder session. It is important to emphasize, however, that the presence of all of these odors during a session in which an intruder is attacked is probably inevitable for several reasons. First, it has been known for some time that the development and maintenance of strong social dominance require that rats reside in mixed-sex cages (e.g., Barnett, 1960; Blanchard \& Blanchard, 1977; Flannelly, Flannelly, \& R. J. Blanchard, 1984). Second, the appearance of a high level of aggressive behavior requires that such colonies have repeated agonistic encounters with younger conspecific intruders (Blanchard \& Blanchard, 1977; Blanchard, Takahashi, \& Blanchard, 1977; Williams, 1982). Finally, as was observed in Experiment 1, it is not unusual for both of the male residents of an aggressive colony to attack and bite the intruder (Williams \& Lierle, 1988). Testing subjects with samples of bedding containing all of the odors from the alpha colonies, at the current stage of this research, was also considered to be ideal from an ethological point of view because these odors are typically present when dominance relationships are established and maintained in the wild (Barnett, 1958; Blanchard \& Blanchard, 1977; Flannelly, Flannelly, \& R. J. Blanchard, 1984). Although the previously mentioned conspecific odors are usually associated with agonistic behavior in both laboratory and wild male rats, we are now in the process of attempting to determine the degree to which each of the component odors is capable of eliciting various types of conditioned fear reactions.

More relevant to the objectives of the present research is the fact that the results of Experiment 1 clearly demonstrate that giving previously attacked rats a session of exposure to alpha-colony odors prior to the prod-shock test results in the attenuation of fear-mediated suppression of burying and increments in freezing during the prod-shock test in which alpha-colony odors are present. This finding is consistent with those of other researchers who have used similar exposure procedures to reduce the fear of shock signals following avoidance learning (Baum, 1970; Mineka, 1979; Levis, 1989). The results of Experiment 1 also indicate that a long-term (i.e., 12-h) exposure to the alpha-colony odors is significantly more effective in reducing fear-mediated changes in burying and freezing than is a short-term (i.e., 2-h) exposure. This result is in agreement with the findings of previous studies that have reported that the total amount of CS exposure is a critical variable in overcoming fear reactions (Levis, 1989; Mineka \& Keir, 1983).

The results of Experiment 2 replicate the findings of Williams and Scott (Experiment 2, 1989) in showing that the presence of cat odors during prod-shock testing results in rats showing exploratory movements, with an outstretched posture, as opposed to prod burying. Blanchard and his colleagues have recently claimed that this type of exploration in places where a cat has been represents an example of risk-assessment defensive behavior (Blanchard \& Blanchard, 1989; Blanchard, Blanchard, \& Hori, 1989). However, in contrast with the findings of Williams and Scott (Experiment 2, 1989), the subjects in Experiment 2 of this study showed significant levels of freezing following the presentation of the prod shock. This may have been due to the fact that the two-cat-exposure method employed in this experiment was found to be more stressful (i.e., producing a higher percentage of freezing during the exposure session) than was the one-cat-exposure method used by Williams and Scott. More importantly, the results of Experiment 2 showed that a 12-h pretest exposure to the cat odors was effective in attenuating subsequent prodshock freezing when subjects were tested in the presence of cat odors. This finding, particularly given the results of Experiment 1, appears to be in agreement with several studies that have found exposure methods to be effective in reducing phobic reactions (e.g., Barlow \& Waddell, 1985; Chambless \& Goldstein, 1982; Marks, 1981; Mineka, 1987; O'Brien \& Barlow, 1984).

In contrast with the results observed with the alphacolony odors in Experiment 1, exposure to cat odors in Experiment 2 was clearly found to be less effective in overcoming fear-mediated reactions during subsequent prod-shock tests. In fact, in a 12-h pretest exposure to cat odors, the subjects did not show an increase in prod burying. The difference between the pretest-exposure effects seen in Experiments 1 and 2 might be based on differences between the total amounts of conditioned and unconditioned fear that were elicited by alpha-colony and cat odors, respectively, that were present during testing. The results of Experiment 1 and the findings of Williams and Scott (Experiment 1, 1989) indicate that alpha-colony odors did not elicit fear reactions during subsequent prodshock tests unless rats had previously been attacked. Therefore, it is believed that the alpha-colony odors became conditioned fear stimuli during the alpha-attack session in which the subjects experienced repeated attacks and painful bites from the aggressive residents. Consistent with this associative interpretation, it is also believed that both the 2-h and the 12-h pretest-exposure sessions 
with the alpha-colony odors, without the aggressive conspecific(s), resulted in the experimental extinction of conditioned fear.

Williams and Scott (Experiment 2, 1989) concluded that cat odors (i.e., cat hair and soiled litter), in contrast with alpha-colony odors, were unconditioned fear stimuli because they completely suppressed prod burying in subjects that had not been exposed to a cat. Since the stressful twocat-exposure procedure that was used in Experiment 2 involved these same odors, it is believed that the fear elicited by these unconditioned odors was augmented during the cat-exposure session by means of conditioning and/or sensitization processes (see Williams \& Barber, 1990, for a further discussion of this topic). If this were the case, the reduction of fear of cat odors would require the involvement of both associative (i.e., extinction) and nonassociative processes. Such nonassociative, fear-reducing processes might include a central habituation of the emotional response to the feared stimulus (Kamin, 1961; Mis \& Moore, 1973) or the formation of an opponent b-process (Randich \& LoLordo, 1979; Solomon \& Corbit, 1974). The present researchers are currently examining the pretest-exposure effects of cat odors by comparing various cat-exposure procedures with no-cat-exposure control groups, in order to learn more about the associative and nonassociative processes that influence fear reactions when this type of predatory stressor is used.

\section{REFERENCES}

Barlow, D. H., \& Waddell, M. T. (1985). Agoraphobia. In D. H. Barlow (Ed.), Clinical handbook of psychological disorders (pp. 169). New York: Gilford Press.

BARNETT, S. A. (1958). An analysis of social behaviour in wild rats. Proceedings of the Zoological Society of London, 130, 107-152.

BARNETT, S. A. (1960). Social behaviour among tame rats and among wild-white hybrids. Proceedings of the Zoological Society of London, 134, 611-621.

Baum, M. (1970). Extinction of avoidance responding through response prevention (flooding). Psychological Bulletin, 74, 276-284.

Blanchard, R. J., \& BlanChard, D. C. (1971). Defensive reactions in the albino rat. Learning \& Motivation, 2, 351-362.

BlANCHARD, R. J., \& BLANCHARD, D. C. (1977). Aggressive behavior in the rat. Behavioral Biology, 21, 197-224.

BlaNCHARD, R. J., \& BlaNCHARD, D. C. (1989). Antipredator defensive behaviors in a visible burrow system. Journal of Comparative Psychology, 103, 70-82.

Blanchard, R. J., Blanchard, D. C., \& Hori, K. (1989). An ethoexperimental approach to the study of defense. In R. J. Blanchard, P. F. Brain, D. C. Blanchard, \& S. Parmigiani (Eds.), Ethoexperimental approaches to the study of behavior (pp. 114-136). Dordrecht: Martinus Nijhoff.

Blanchard, R. J., Fukunaga, K. K., \& Blanchard, D. C. (1976). Environmental control of defensive reactions to a cat. Bulletin of the Psychonomic Society, 8, 179-181.

Blanchard, R. J., TaKahashi, L. K., \& Blanchard, D. C. (1977). The development of intruder attack in colonies of laboratory rats. Animal Learning \& Behavior, 5, 365-369.

Chambless, D. L., \& Goldstein, A. J. (1982). Agoraphobia: Multiple perspectives on theory and treatment. New York: Wiley.

FANSELOW, M. S., \& LESTER, L. S. (1988). A functional behavioristic approach to aversively motivated behavior: Predatory imminence as a determinant of the topography of defensive behavior. In R. C. Bolles \& M. D. Beecher (Eds.), Evolution and leaming (pp. 185-212). Hillsdale, NJ: Erlbaum.

Fanselow, M. S., Sigmundi, R. A., \& Williams, J. L. (1987). Response selection and hierarchical organization of species-specific defensive reactions: The relationship between freezing, flight, and defensive burying. Psychological Record, 37, 381-386.

FlanNelly, K. J., FlanNelly, L., \& BlanChard, R. J. (1984). Adult experience and the expression of aggression: A comparative analysis. In K. J. Flannelly, R. J. Blanchard, \& D. C. Blanchard (Eds.), Biological perspectives on aggression (pp. 207-259). New York: Alan Liss.

KAMIN, L. J. (1961). Apparent adaptation effects in the acquisition of a conditioned emotional response. Canadian Journal of Psychology, 15, 176-188.

LeSTER, L. S., \& FANSELOW, M. S. (1985). Exposure to a cat produces opioid analgesia in rats. Behavioral Neuroscience, 4, 756-759.

Levis, D. J. (1989). The case for a return to two-factor theory of avoidance: The failure of non-fear interpretations. In S. B. Klein \& R. R. Mowrer (Eds.), Contemporary learning theories: Pavlovian conditioning and the status of traditional learning theory (pp. 227-278). Hillsdale, NJ: Erlbaum.

MAIER, S. F. (1986). Stressor controllability and stress-induced analgesia. In D. D. Kelley (Ed.), Annals of the New York Academy of Sciences, 467, 55-71.

MARKS, I. M. (1981). Cure and care of neuroses: Theory and practice of behavioral psychotherapy. New York: Wiley.

MiNEKA, S. (1979). The role of fear in theories of avoidance learning, flooding, and extinction. Psychological Bulletin, 86, 985-1010.

MiNEKA, S. (1987). A primate model of phobic fears. In H. Eysenck \& I. Martin (Eds.), Theoretical foundations of behavior therapy (pp. 81-111). New York: Plenum.

MineKa, S., \& KEIR, R. (1983). The effects of flooding on reducing snake fear in rhesus monkeys: 6-month follow-up and further flooding. Behaviour Research and Therapy, 21, 527-535.

Mis, R. W., \& MOORE, J. W. (1973). Effects of preacquisition UCS exposure on classical conditioning of the rabbit's nictitating membrane. Leaming \& Motivation, 4, 108-114.

O'Brien, G. T., \& Barlow, D. H. (1984). Agoraphobia. In S. M. Turner (Ed.), Behavioral treatment of anxiety disorders (pp. 143-185). New York: Plenum.

Peacock, E. L., \& Wong, P. T. P. (1982). Defensive burying in the rat: A behavioral field analysis. Animal Learning \& Behavior, 10, 103-107.

Pinel, J. P. J., \& Treit, D. (1978). Burying as a defensive response in rats. Journal of Comparative \& Physiological Psychology, 92, 708-712.

Pinel, J. P. J., \& Treit, D. (1981). The conditioned defensive burying paradigm and behavioral neuroscience. In T. E. Robinson (Ed.), Behavioral contributions to brain research (pp. 212-234). Oxford, U.K.: Oxford University Press.

RANDich, A. \& LoLoRDO, V. M. (1979). Associative and nonassociative theories of the UCS pre-exposure phenomenon: Implications for Pavlovian conditioning. Psychological Bulletin, 86, 523-548.

Solomon, R. L., \& CoRBIT, J. D. (1974). An opponent-process theory of motivation: I. Temporal dynamics of affect. Psychological Review, 81, 119-145.

TREIT, D. (1985). Animal models for the study of anti-anxiety agents: A review. Neuroscience \& Biobehavioral Review, 9, 203-222.

WiluIAMS, J. L. (1982). Influence of shock controllability by dominant rats on subsequent attack and defense behaviors toward colony intruders. Animal Learning \& Behavior, 10, 305-313.

Wiluiams, J. L. (1987a). Effects of shock controllability on alpha male aggression and defense, defeat of intruders, and defensive burying. Psychological Record, 37, 369-380.

Wiluiams, J. L. (1987b). Influence of conspecific stress odors and shock controllability on conditioned defensive burying. Animal Learning \& Behavior, 15, 333-341.

WiLLIAMS, J. L. (1989). Ethoexperimental analysis of stress, contex- 
tual odors, and defensive behaviors. In R. J. Blanchard, P. F. Brain, D. C. Blanchard, \& S. Parmigiani (Eds.), Ethoexperimental approaches to the study of behavior (pp. 214-228). Dordrecht: Martinus Nijhoff.

Williams, J. L., Barber, R. G. (1990). Effects of cat exposure and cat odors on subsequent amphetamine-induced stereotypy. Pharmacology, Biochemistry, \& Behavior, 36, 375-380.

WILliAMS, J. L., \& LIERLE, D. M. (1988). Effects of repeated defeat by a dominant conspecific on subsequent pain sensitivity, open-field activity, and escape learning. Animal Leaming \& Behavior, 16, 477-485.

Williams, J. L., SCOTT, D. K. (1989). Influence of conspecific and predatory stressors and their associated odors on defensive burying and freezing responses. Animal Learning \& Behavior, 17, 383-393.

Wiluiams, J. L., Worland, P. D., \& Smith, M. G. (1990). Defeatinduced analgesia in the rat: Effects of conditioned odors, naltrexone, and extinction. Joumal of Experimental Psychology: Animal Behavior Processes, 16, 345-357.
WINER, B. J. (1971). Statistical principles in experimental design. New York: McGraw-Hill.

\section{NOTE}

1. It is important to note that the term "defeat" (or "defeated") in this study simply refers to the fact that the intruders were attacked and bitten during the 15-min session by colony residents that were found to be consistently aggressive in previous colony-intruder tests. In contrast to the work of previously mentioned researchers (e.g., Miczek, Rodgers) who have studied defeat in mice, the use of this term in the present paper does not imply that a psychological state or submissive postures were specifically manipulated or measured by the experimenter.

(Manuscript received November 22, 1989; revision accepted for publication April 19, 1990.) 